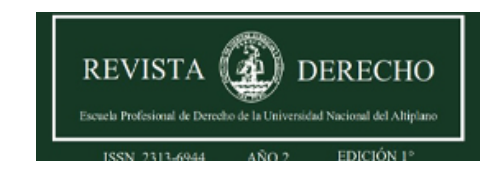

Revista de Derecho

ISSN: 2313-6944

ISSN: 2707-9651

revistaderecho@unap.edu.pe

Universidad Nacional del Altiplano

Perú

\title{
CRIPTOACTIVOS. RETOS Y DESAFÍOS NORMATIVOS
}

\author{
Caballero Trenado, Laura \\ CRIPTOACTIVOS. RETOS Y DESAFÍOS NORMATIVOS \\ Revista de Derecho, vol. 6, núm. 1, 2021 \\ Universidad Nacional del Altiplano, Perú \\ Disponible en: https://www.redalyc.org/articulo.oa?id=671870928010 \\ DOI: https://doi.org/10.47712/rd.2021.v6i1.124
}

\section{(c) (1)}

Esta obra está bajo una Licencia Creative Commons Atribución 4.0 Internacional. 
Artículos de naturaleza variada

\section{CRIPTOACTIVOS. RETOS Y DESAFÍOS NORMATIVOS}

\author{
Laura Caballero Trenado* \\ Universidad Internacional de La Rioja, España \\ laura.caballero@unir.net
}

CRYPTOACTIVES. REGULATORY CHALLENGES AND DARES

(DD https://orcid.org/0000-0001-9749-2395
DOI: https://doi.org/10.47712/rd.2021.v6i1.124

Redalyc: https://www.redalyc.org/articulo.oa? $\mathrm{id}=671870928010$

Barrio M.. Criptoactivos. Retos y desafíos normativos. 2021. Madrid. La Ley (Wolters Kluwer) Recepción: 13 Abril 2021 Aprobación: 15 Abril 2021 Publicación: 15 Abril 2021

\section{Resumen:}

Bitcoin ha superado la barrera psicológica de los 60.000 dólares por unidad en el mes de abril de 2021 y todo apunta a que alcanzará cotas mayores en los años venideros. Como parte del ecosistema Fintech, que está conformado por una amalgama de criptoactivos, Bitcoin es tal vez la criptomoneda más conocida junto a Ethereum, pero no la única, pues ambas son "sólo la punta del iceberg de esta transformación digital de las finanzas” (Barrio, 2021). El inexorable avance de estos criptoactivos, cuyo sustrato tecnológico se basa en blockchain, representa un desafío legal sin precedentes al que el jurista debe aproximarse desde diversos sectores normativos. De esta ingente labor se ocupa Moisés Barrio Andrés en la monografía Criptoactivos. Retos y desafíos normativos, que ha dirigido junto a un nutrido grupo de destacados expertos en la materia.

Palabras CLAVE: criptoactivos, criptomonedas, Bitcoin, blockchain, normativa.

\section{Abstract:}

Bitcoin has overcome the psychological barrier of \$ 60,000 per unit in the month of April 2021 and everything indicates that it will reach higher levels in the coming years. As part of the Fintech ecosystem, which is made up of an amalgam of crypto assets, Bitcoin is perhaps the best-known cryptocurrency along with Ethereum, but not the only one, since both are "only the tip of the iceberg of this digital transformation of finance" ( Neighborhood, 2021). The inexorable advance of these crypto assets, whose technological substrate is based on blockchain, represents an unprecedented legal challenge that the jurist must approach from various regulatory sectors. Moisés Barrio Andrés deals with this enormous work in the monograph Criptoactivos. Regulatory Challenges and Challenges, which he has led together with a large group of leading experts in the field.

KEYWORDS: Legal customs, Gender, Gender perspective, Interculturality.

Planteada en torno a dieciocho capítulos, el estudio abarca desde los aspectos generales inherentes a las criptofinanzas hasta las cuestiones jurídico-sustantivas y jurídico-procesales más relevantes inherentes a su circulación en el tráfico jurídico.

De este modo, en el primer capítulo (La nueva era de las criptofinanzas), que rubrican María Panga Landa y Diego García Novillo, el lector encontrará una exposición prolija pero sucinta y muy pedagógica de las implicaciones de la digitalización en la automatización de la contratación en los mercados de valores, en general, y del impacto de la implementación de blockchain en estos procesos, en particular.

\section{NotAS DE AUTOR}

* Profesora Doctora en la Universidad Internacional de La Rioja

laura.caballero@unir.net 
Del segundo capítulo se ocupa el director de esta obra, Moisés Barrio Andrés. Titulado Concepto y clases de criptoactivos, constituye una aproximación muy útil para entender la idea clave que subyace detrás de las criptofinanzas: el funcionamiento de la tecnología blockchain.

En este sentido, blockchain es una suma de tecnologías (DLT o Distributed Ledger Techologies) que tiene unas características cuyo objetivo principal es posibilitar la transferencia de valor. En el estudio de estas notas se abunda en el siguiente capítulo (Fundamentos tecnológicos de las criptomonedas), que firma Jesús Herencia Antón.

Los rasgos de blockchain -encriptación, inmutabilidad y tokenización- posibilitan su circulación, pero la verdadera expansión y democratización en el uso de los criptoactivos dependerá de la irrenunciable confianza que genere en el ciudadano. Desde esta perspectiva, el autor del siguiente capítulo-Algunos casos de uso-, Rafael García del Poyo Vozcaya, expone ejemplos concretos de criptoactivos que están llamados a protagonizar esta eclosión. Entre otros, stablecoins, coomodities y tokens.

La hoja de ruta de la digitalización sostenible del sector financiero es asimétrica. Prueba de ello es la táctica que los distintos países han seguido a la hora de regular los criptoactivos. En el siguiente capítulo -Hacia una nueva regulación europea: el Digital Finance Package-, que firma Eduardo Novella González del Castillo, se desgranan los aspectos esenciales del DFP desde una perspectiva triple: i) el contexto, significo y la naturaleza jurídica del DFP; ii) la estrategia para un mercado financiero digital y para los pagos minoristas, y iii) las cuatro propuestas legislativas presentadas por la Comisión Europea para afrontar este nuevo reto.

Sin abandonar la perspectiva regional europea, el siguiente capítulo, que también está a cargo de Eduardo Novella -El futuro Reglamento europeo para un mercado de criptoactivos (Propuesta MICA)-, aborda el futuro Reglamento (UE) relativo a los mercados de criptoactivos, que modificará el actual instrumento normativo que regula esta materia -la Directiva (UE) 2019/1937- (conocida como la Propuesta MICA).

"Muchos de los principales obstáculos y limitaciones al desarrollo de los criptoactivos son debidos a la ausencia de un marco legal adecuado que proporcione un minimo de garantias y seguridad jurídica"[1]. Y este desafío es global, pues el operador jurídico involucrado con criptoactivos se enfrenta a ordenamientos jurídicos que también están ayunos de proporcionar un marco legal adecuado que proporcione un mínimo de garantías y seguridad jurídica.

Por ejemplo, en Latinoamérica, región en la que existe un mercado de criptoactivos en expansión, la regulación es desigual. De algunas de las razones que explican este crecimiento se ocupa Dino Carlos Caro Coria en el capítulo titulado La regulación de los criptoactivos en Latinoamérica, que apunta a la falta de regulaciones regionales y locales, la ausencia de una autoridad central y a la no intervención del Estado mediante imposiciones tributarias o reglas que transparenten la trazabilidad de las operaciones con criptomonedas como las causas que explican dicha expansión.

La evolución de la tecnología blockchain ha acelerado el estudio y puesta en práctica de proyectos piloto sobre la posible emisión de monedas digitales de bancos centrales. Esta posibilidad cristaliza en la proyección del Euro digital, de cuyo análisis en clave jurídica se ocupa el autor del capítulo rubricado Hacia un Euro digital, Alfredo Muñoz García.

Pero el elenco de posibilidades que introducen los criptoactivos no se agota en prototipos de monedas. Espoleado por las nuevas tecnologías, este universo y el corolario de opciones infinitas que introducen los criptoactivos proyectan nuevos modelos de negocios. Es el caso de los sandboxes, por ejemplo, que son espacios delimitados en los que las empresas interesadas pueden realizar una serie de pruebas, de acuerdo con un plan aprobado y bajo supervisión de un regulador. $\mathrm{Al}$ análisis de los distintos modelos que han innovado recientemente el sector financiero español se consagra el autor del siguiente capítulo ( $E l$ "Sandbox" español), José Delgado Larena-Avellaneda.

Si las criptomonedas tienen una naturaleza fungible, no ocurre lo mismo con otros activos físicos, como los inmuebles, por ejemplo, que son activos no fungibles. La necesidad de transferir valor es, precisamente, lo que subyace en el fenómeno de la tokenización de activos. 
En este sentido, el empleo de una forma digital para activos no digitales -como una propiedad inmobiliariahace imprescindible realizar algún tipo de transformación o proyección de esos activos existentes en el mundo físico al mundo virtual de la cadena de bloques, y a esta necesidad es a lo que responde la tokenización.

A esta tarea precisamente -la tokenización de activos físicos no fungibles- se consagra el autor del siguiente capítulo (La tokenización de activos), Jesús Sieira Gil, quien ofrece un análisis en clave jurídica esta nueva forma de acreditar un hecho, acto o negocio jurídico, con especial atención en los activos de naturaleza inmobiliaria.

Emisión, representación y gestión de criptoactivos es el sugerente título del siguiente capítulo, que firma Javier Ibáñez Jimenez, y en el que el autor aborda la polisemia de base que subyace a las definiciones legales de los criptoactivos, al tiempo que ofrece soluciones jurídicas a esta equivalencia funcional de los distintos términos que son dispares en diferentes ordenamientos jurídicos, como son la homogeneización y armonización normativa.

Ana Fernández-Tresguerres García entronca el interés creciente del fenómeno DLT con el gobierno corporativo de las sociedades de capital en el siguiente capítulo (Criptoactivos: incidencia en el gobierno corporativo de las sociedades de capital), en el que se detiene de manera especial en las sociedades admitidas a cotización en mercados bursátiles o alternativos.

Cinco son los aspectos jurídico-sustantivos de los criptoactivos de los que se ocupan los capítulos subsiguientes.

Del primero de ellos -la fiscalidad- se ocupa José Almudi Cid en el capítulo que rubrica como La fiscalidad de los criptoactivos, en el que el autor aborda la imposición sobre la renta, sobre el patrimonio y sobre el consumo de estos activos. Completa el análisis una pormenorizada relación de las obligaciones informativas inherentes a la tenencia de bienes en el extranjero.

Los riesgos capaces de capturar la atención de la ultima ratio del ordenamiento jurídico son múltiples. A los más significativos está consagrado el siguiente capítulo -titulado Riesgospenales de la posesión, adquisición, venta e intercambio de criptoactivos-, que rubrica Óscar Morales García.

Sin abandonar la vertiente penalista, Ofelia Tejerina Rodríguez aborda en el capítulo Criptoactivos y ciberseguridad la concreta problemática que introduce la generalización como método de pago con criptomonedas, cuestión que analiza desde la doble consideración que estamos ante un instrumento de ciberdelincuencia y ante un objetivo de ésta al mismo tiempo.

La ciberseguridad es causa y consecuencia, a su vez, de un sinfín de ciberiesgos, que son desbrozados pormenorizadamente por Alberto Muñoz Villareal en Ciberiesgos y seguros: los riesgos de los criptoactivos y su aseguramiento.

Blockchain es una tecnología mediante la que se crea una cadena digital de registros con enlaces. El resultado es un registro único, irrepetible e inmutable. Con blockchain la gestión de las transacciones se descentraliza, puesto que no hay necesidad de intermediarios. Sin embargo, a pesar de que la identidad del usuario está oculta detrás de una dirección pública, la información de estas transacciones puede quedar al albur de la verificación por parte de un tercero, por lo que la principal fortaleza de esta tecnología -la transparenciapodría ser también, paradójicamente, su punto débil más importante (Caballero, 2019)[2]. El análisis del binomio transparencia/privacidad se estudia en el penúltimo capítulo de la obra (Criptoactivos y privacidad), que firma Noemí Brito Izquierdo.

Cierra esta monografía un capítulo dedicado al estudio de los aspectos jurídico-procesales más relevantes que introducen las litis sobre criptoactivos en los procedimientos civiles. Aspectos procesales es el título del capítulo que suscribe Yolanda Ríos López y en el que la autora analiza desde la perspectiva del Derecho probatorio cuestiones como las fuentes y los medios de prueba, sobre todo, la documental, en la que la autora hace una distinción entre blockchain como documento privado y documento público, pues el alcance de su valor probatorio en sede de prueba documental, lógicamente, varía. 
Como puede comprobarse, Criptoactivos. Retos y desafíos es una obra que se anticipa, en clave prospectiva, a un nuevo escenario financiero que el conjunto de tecnologías que proyecta blockchain está llamado a revolucionar.

Por lo anterior, estamos ante un estudio que abona los aspectos jurídicos clave para dar respuesta a este imparable tsunami tecnológico o, si se prefiere, ante una propuesta de lege ferenda. Y, en cualquier caso, ante un referente de obligada consulta para juristas, investigadores y estudiosos de la materia. 